\title{
DETECTION OF CERVICAL LYMPH NODE MICROMETASTASES IN PATIENTS WITH SQUAMOUS CELL CARCINOMA OF THE ORAL CAVITY, PHARYNX AND LARYNX
}

\author{
Petr Čelakovský, David Kalfeřt ${ }^{1}$, Katarína Smatanová ${ }^{1}$, Viktor Chrobok ${ }^{1}$, Jan Laco ${ }^{2}$
}

\begin{abstract}
Department of Otorhinolaryngology and Head and Neck Surgery, University Hospital Hradec Králové, Charles University in Prague, Faculty of Medicine in Hradec Králové, Czech Republic; The Fingerland Department of Pathology, University Hospital Hradec Králové, Charles University in Prague, Faculty of Medicine in Hradec Králové, Czech Republic
\end{abstract}

\begin{abstract}
Summary: Background: The goal of this prospective study was to determine the frequency of micrometastases in patients with squamous cell carcinoma (SCC) of the oral cavity, pharynx and larynx in whom elective neck dissection was indicated (cN0). Patients and Methods: A total of 12 patients (10 males and 2 females) were enrolled in the study. The age ranged 42-73 years (median 62 years). Elective neck dissection was performed in all patients ( 8 ipsilateral, 4 bilateral) and a total of 256 lymph nodes were removed and sent for microscopic examination. Results: The presence of tumor cells in cervical lymph nodes was found in 5/12 (42\%) patients. Micrometastases of SCC were found in two patients and isolated tumor cells (ITC) in two other patients. In the remaining one patient with oropharyngeal SCC, a micrometastasis of papillary thyroid carcinoma (PTC) was detected. Positive lymph nodes were localized in level II in three patients with SCC of larynx, hypopharynx and tongue base, respectively, in level I in one patient with SCC of oral tongue and in level III in one patient with PTC. Conclusion: Our results indicate that SCC of head and neck has a high potential for creating micrometastases which frequency is higher compared to clinically detected macrometastases. Therefore, elective neck dissection or radiotherapy of the neck should be considered in patients with high risk of occult metastases or micrometastases.
\end{abstract}

Key words: Head and neck squamous cell carcinoma; Occult metastases; Micrometastases; Isolated tumor cells

\section{Introduction}

The presence of cervical lymph node metastases is nowadays one of the most important prognostic factors of head and neck squamous cell carcinoma (HNSCC), particularly in HPV-negative tumors. It is recommended to differentiate macrometastases from occult metastases, micrometastases and isolated tumor cells (ITC). Even if the prognosis of disease in presence of ITC is still unclear, presence of micrometastases has been proven to be clinically significant. Because it is difficult to detect micrometastases and ITC by common diagnostic methods or by standard histopathological examinations, immunohistochemical and molecular methods are often used for their detection.

The aim of our study was to determine the frequency of micrometastases and ITC in HNSSC patients, who were indicated for elective neck dissection.

\section{Materials and methods}

Prospective study with approval of regional ethical committee was performed. All patients with squamous cell carcinoma (SCC) of the oral cavity, pharynx and larynx, indicated for elective neck dissection (cN0) in time period from 1 January 2012 to 31 December 2013, were enrolled in the study. Our study group represents a total number of 12 patients (10 males and 2 females) treated in the Department of Otorhinolaryngology and Head and Neck Surgery, University Hospital in Hradec Králové. The age ranged 42-73 years (median 62 years). All cases of laryngeal tumors were T4 stages, whereas in cases of pharyngeal tumors the size ranged between T1-T4 stages (Table 1). Elective neck dissection (cN0) was performed in all patients and a total of 256 lymph nodes were removed and sent for microscopic examination. The extent of neck dissection was modified by the size and location of primary tumor $(8 \times$ ipsilateral, $4 \times$ bilateral, in most cases levels I-IV, or II-V).

The pathologic evaluation and reporting of lymph nodes generally followed the 2005 ASCO (American Society of Clinical Oncology) Guideline (1), with attention to the recently proposed protocol recommendations (2).

The fibro-fatty tissue was carefully dissected to identify all lymph nodes. The number and the size of the largest lymph node were recorded. All lymph nodes were cut into sections not thicker than $2 \mathrm{~mm}$ through and parallel to the longest axis. All sections were embedded and submitted for 
microscopic examination. Initially, one hematoxylin-eosin (HE) - stained section was cut from each block for light microscopy. If the lymph node was classified as negative, additional step sections at $200-\mu \mathrm{m}$ interval were cut through the block. These were stained with HE, except for one section which was used for immunohistochemical detection of cytokeratins (CK) (dilution 1 : 100, clone AE1/AE3, Dako (Glostrup, Denmark)).

The pathologic reporting of lymph nodes were as follows (3):

- negative - reactive changes, sinus histiocytosis, lymphostasis, benign inclusions etc.;

- isolated tumor cells - small clusters of cells not greater than $0.2 \mathrm{~mm}$, or nonconfluent or nearly confluent clusters of cells not exceeding 200 cells in a single cross sections;

- micrometastasis - individual tumor deposit larger than $0.2 \mathrm{~mm}$ but not exceeding $2.0 \mathrm{~mm}$;

- macrometastasis - individual tumor deposit larger than $2.0 \mathrm{~mm}$.

\section{Results}

Presence of tumor cells in the lymph nodes was found in $5 / 12(42 \%)$ patients.

Micrometastases of SCC were found in two patients (Fig. 1 and 2). One patient had an isolated micrometastasis in one lymph node and the second patient had three micrometastases in two lymph nodes. Furthermore, ITC in one lymph node were found in two other patients. In the remaining one patient with oropharyngeal SCC, a micrometastasis of papillary thyroid carcinoma (PTC) was detected (Table 1).

Positive lymph nodes were localized in level II in three patients with SCC of larynx, hypopharynx and tongue base, respectively, in level I in one patient with SCC of oral tongue and in level III in one patient with PTC. Micrometastases of SCC and ITC were found in patients with T2-T4 tumors (Table 1).

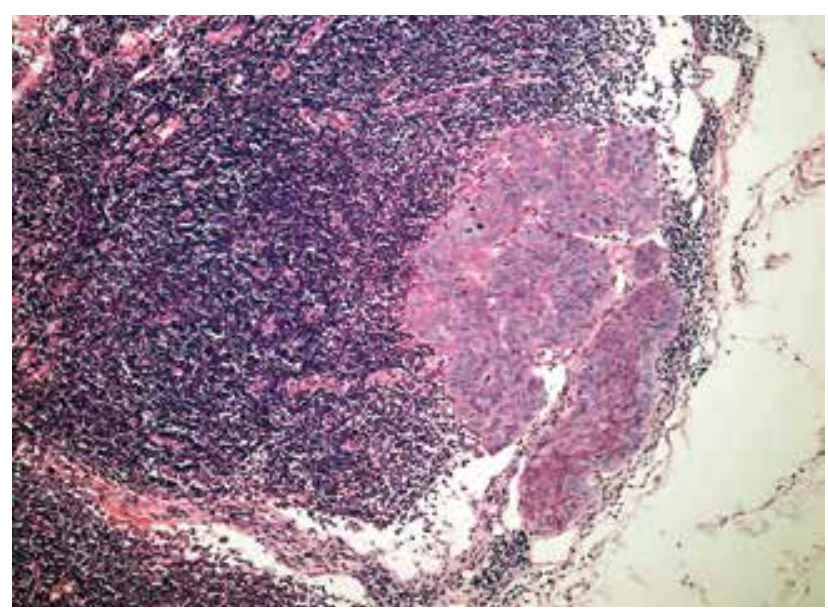

Fig. 1: Lymph node with micrometastasis of poorly differentiated squamous cell carcinoma measuring $0.6 \mathrm{~mm}$ in subcapsular sinus (hematoxylin-eosin, original magnification $100 \times$ ).

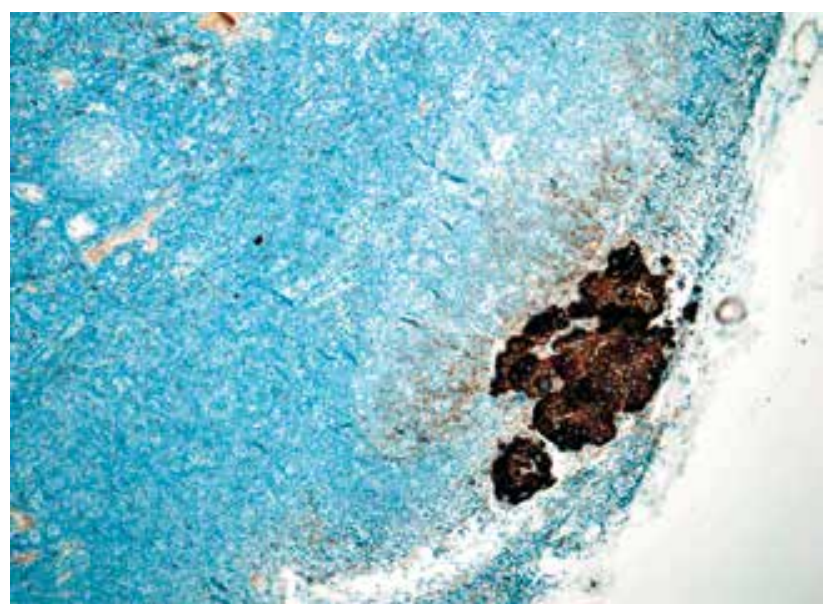

Fig. 2: Diffuse expression of cytokeratins in metastasizing tumor cells (original magnification 100×).

Tab. 1: Group of the patients.

\begin{tabular}{|l|l|c|l|l|c|l|l|}
\hline $\begin{array}{l}\text { Patient } \\
\text { No. }\end{array}$ & Sex & $\begin{array}{c}\text { Age } \\
\text { (yrs.) }\end{array}$ & $\begin{array}{l}\text { Site of primary } \\
\text { tumor }\end{array}$ & T stage & $\begin{array}{c}\text { Number of } \\
\text { lymph nodes }\end{array}$ & $\begin{array}{l}\text { Microscopic } \\
\text { findings }\end{array}$ & $\begin{array}{l}\text { Level of affected lymph } \\
\text { nodes (laterality) }\end{array}$ \\
\hline 1 & male & 61 & tonsil & T1 & 12 & negative & - \\
\hline 2 & female & 66 & body of tongue & T2 & 5 & negative & - \\
\hline 3 & male & 73 & tonsil & T1 & 19 & micrometastasis (PTC) & III, ipsilateral \\
\hline 4 & male & 73 & base of tongue & T4a & 15 & ITC (SCC) & I, ipsilateral \\
\hline 5 & male & 73 & base of tongue & T3 & 58 & ITC (SCC) & II, ipsilateral \\
\hline 6 & male & 63 & larynx & T4a & 45 & negative & - \\
\hline 7 & male & 50 & body of tongue & T1 & 27 & negative & - \\
\hline 8 & male & 59 & tonsil & T2 & 24 & negative & - \\
\hline 9 & male & 61 & tonsil & T1 & 2 & negative & - \\
\hline 10 & male & 42 & body of tongue & T2 & 14 & negative & - \\
\hline 11 & male & 62 & hypopharynx & T2 & 19 & micrometastasis (SCC) & II, contralateral \\
\hline 12 & female & 68 & larynx & T4a & 16 & micrometastasis (SCC) & II, ipsilateral \\
\hline
\end{tabular}

Abbreviations: ITC $=$ isolated tumor cells, $\mathrm{SCC}=$ squamous cell carcinoma, $\mathrm{PTC}=$ papillary thyroid carcinoma 


\section{Discussion}

In cases of diagnosed metastases in cervical lymph nodes one ought to differentiate macrometastases from occult metastases, micrometastases and ITC. Macrometastasis is a lymph node suspicious on clinical examination or radiological images. Occult or subclinical metastasis is not detectable by imaging methods or physical examination of the lymph node. Micrometastasis is tumor lymph node deposit larger than $0.2 \mathrm{~mm}$ but not exceeding $2.0 \mathrm{~mm}$.

Tumor cell deposits smaller than $0.2 \mathrm{~mm}$ are classified as $\operatorname{ITC}(3,4)$. In addition, there is another criterion for diagnosis of ITC as a cluster not exceeding 200 tumor cells in one slide. Furthermore, ITC are divided into those detectable by light microscopy or into those detectable by immunohistochemistry or molecular methods only $(4,5)$. Nowadays, there is no imaging technique which would have as close as $100 \%$ sensitivity or specificity in detecting lymph node metastases. Clinical examination including the newest imaging modalities give false negative results in about $20-30 \%$ cases (6). Microscopic examination of dissected lymph nodes still remains the gold standard for detection of lymph node metastases. However, if a lymph node is examined only by one central section, micrometastases, which are typically localized in the subcapsular sinuses of lymph nodes, are likely missed (7). For this reason, it is very difficult to diagnose micrometastases by routine histopathological examinations $(6,8)$. Many authors state significantly increased detection rate of micrometastases by examining serial histological sections in combination with immunohistochemical or molecular procedures $(5,9-11)$. However, wider use of these methods in clinical practice is prevents their time consuming and higher cost.

Detection of micrometastases by immunohistochemistry has been a priority especially in the breast cancer. Dowlatshahi was one of the first authors to write about high occurrence of micrometastases not detected by standard histological examination (12). After examination of sentinel lymph nodes of 52 patients with breast carcinoma by standard histological examination ( $2 \mathrm{~mm}$ thick sections), 6 patients had positive results. However, after further and more detailed (serial $0.25 \mathrm{~mm}$ thick sections) immunohistochemical examination, the number of positive results increased to $30 / 52(58 \%)$ patients. Many authors in recent years have focused on detection of HNSCC micrometastases using immunohistochemical methods. Positive results in patients with clinical N0 stage varies widely from 2 to $58 \%$ (13-18), which indicates that the methods for detection are not united and the percentage of positive results depends on the experience of the pathologist. In our study, micrometastases or ITC were detected in 5 cases $(42 \%), 4$ patients (33\%) had a metastases of SCC and 1 patient $(9 \%)$ had an accidental finding of PTC micrometastasis.

At present, the prognostic significance of ITC remains unclear. On the other hand, the presence of micrometastases is clinically significant $(8,18-20)$. Nieuwenhuis et al. found that the survival of patients with cN0 but with one or more micrometastases (detected by molecular analysis) was worse compared to patients without micrometastases (10). Similar results were published by $\mathrm{Xu}$ et al. (18-19) and Yamazaki et al. (21). Presence of unrecognized micrometastases or ones left in situ can also explain regional tumor recurrence in patients with $\mathrm{N} 0$ stage or in patients with $\mathrm{N}+$ stage after selective neck dissection. The assumption of micrometastases left in situ turning into clinically significant metastases makes us further indicating elective neck dissection or radiotherapy in HNSCC with higher metastatic potential.

\section{Conclusions}

- HNSSC has a significant potential for creating micrometastases which frequency is higher compared to clinically detected macrometastases.

- Elective neck dissection or radiotherapy of the neck should be considered in patients with high risk of occult metastases or micrometastases.

\section{Acknowledgements}

The study was supported by the project (Ministry of Health, Czech Republic) for conceptual development of research organization 00179906 (research number 8154), by the programme PRVOUK P37/11 and by the project LM2010004.

Ethical standard: The study has been approved by the local ethics committee (reference number 201206 S23P) and has been performed in accordance with the ethical standards laid down in the 1964 Declaration of Helsinki (version 2002).

\section{References}

1. Lyman GH, Giuliano AE, Somerfield MR, et al. American Society of Clinical Oncology guideline recommendations for sentinel lymph node biopsy in early-stage breast cancer. J Clin Oncol 2005; 23: 7703-20.

2. Weaver DL. Pathology evaluation of sentinel lymph nodes in breast cancer: protocol recommendations and rationale. Mod Pathol 2010; 23 Suppl 2: S26-32.

3. Sobin LH, Gospodarowicz MK, Wittekind C. TNM Classification of Malignant Tumours, 7th Edition. Wiley-Blackwell; 2009.

4. Devaney KO, Rinaldo A, Ferlito A. Micrometastases in cervical lymph nodes from patients with squamous carcinoma of the head and neck: should they be actively sought? Maybe. Am J Otolaryngol 2007; 28: 271-4.

5. Hamakawa H, Fukuzumi M, Bao Y, Sumida T, Kayahara H, Onishi A, et al. Keratin mRNA for detecting micrometastasis in cervical lymph nodes of oral cancer. Cancer Lett 2000; 160: 115-23.

6. Barrera JE, Miller ME, Said S, Jafek BW, Campana JP, Shroyer KR. Detection of occult cervical micrometastases in patients with head and neck squamous cell cancer. Laryngoscope 2003; 113: 892-6.

7. Ferlito A, Partridge M, Brennan J, Hamakawa H. Lymph node micrometastases in head and neck cancer: a review. Acta Otolaryngol 2001; 121: 660-5.

8. Ferlito A, Rinaldo A, Devaney KO, Nakashiro K, Hamakawa H. Detection of lymph node micrometastases in patients with squamous carcinoma of the head and neck. Eur Arch Otorhinolaryngol 2008; 265: 1147-53.

9. Hamakawa H, Fukizumi M, Bao Y, Sumida T, Onishi A, Tanioka H, et al. Genetic diagnosis of micrometastasis based on SCC antigen mRNA in cervical lymph nodes of head and neck cancer. Clin Exp Metastasis 1999; 17: 593-9.

10. Nieuwenhuis EJ, Leemans CR, Kummer JA, Denkers F, Snow GB, Brakenhoff $\mathrm{RH}$. Assessment and clinical significance of micrometastases in lymph nodes of head and neck cancer patients detected by E48 (Ly-6D) quantitative reverse transcription-polymerase chain reaction. Lab Invest 2003; 83: 1233-40. 
11. Tsujimoto M, Nakabayashi K, Yoshidome K, Kaneko T, Iwase T, Akiyama F, et al. One-step nucleic acid amplification for intraoperative detection of lymph node metastasis in breast cancer patients. Clin Cancer Res 2007; 13:4807-16.

12. Dowlatshahi K, Fan M, Bloom KJ, Spitz DJ, Patel S, Snider HC, Jr. Occult metastases in the sentinel lymph nodes of patients with early stage breast carcinoma: A preliminary study. Cancer 1999; 86: 990-6.

13. Christensen A, Bilde A, Therkildsen MH, Mortensen J, Charabi B, Kirkegaard J, et al. The prevalence of occult metastases in nonsentinel lymph nodes after step-serial sectioning and immunohistochemistry in $\mathrm{cN} 0$ oral squamous cell carcinoma Laryngoscope $2011 ; 121: 294-8$.

14. Ferlito A, Shaha AR, Rinaldo A. The incidence of lymph node micrometastases in patients pathologically staged N0 in cancer of oral cavity and oropharynx. Oral Oncol 2002; 38: 3-5.

15. Mnejja M, Hammami B, Bougacha L, Chakroun A, Charfeddine I, Khabir A, et al. Occult lymph node metastasis in laryngeal squamous cell carcinoma: Therapeutic and prognostic impact. Eur Ann Otorhinolaryngol Head Neck Dis 2010; 127: $173-6$

16. Negm H, Mosleh M, Fathy H, Hareedy A, Elbattawy A. Cytokeratin immunohis- tochemically detected nodal micrometastases in N0 laryngeal cancer: impact on the overall occult metastases. Eur Arch Otorhinolaryngol 2013; 270: 1085-92.

17. Starska K, Lukomski M, Stasikowska O, Lewy-Trenda I. Prognostic significance of matrix metalloproteinases type I expression and tumor front parameters in the presence of lymph node micrometastases in carcinoma of the larynx. Adv Med Sci 2007; 52: 169-73.

18. Xu Y, Zhao X, Guan M, Li B, Zhou Y, Zhou F. Determination of lymph node micrometastases in patients with supraglottic carcinoma. Acta Otolaryngol 2007; 127: $1188-95$.

19. Xu Y, Fei M, Wang J, Zheng L, Chen Y, Liu Q. Clinical significance of micrometastases in lymph nodes from laryngeal squamous cell carcinoma. Am J Otolaryngol 2012; 33: 402-7.

20. Prenzel KL, Holscher AH, Drebber U, Agavonova M, Gutschow CA, Bollschweiler E. Prognostic impact of nodal micrometastasis in early esophageal cancer. Eur J Surg Oncol 2012; 38: 314-8.

21. Yamazaki Y, Chiba I, Hirai A, et al. Clinical value of genetically diagnosed lymph node micrometastasis for patients with oral squamous cell carcinoma. Head Neck 2005; $27:$ 676-81.

Received: $12 / 04 / 2015$

Accepted in revised form: 17/06/2015

\section{Corresponding author:}

David Kalfeřt, MD, Department of Otorhinolaryngology and Head and Neck Surgery, University Hospital Hradec Králové, Sokolská 581, Hradec Králové 500 05, Czech Republic; e-mail: kalfertd@lfhk.cuni.cz, david.kalfert@email.cz 